\title{
Survey of umbilical cord care practices and separation time in healthy new-born in Maiduguri, Nigeria
}

\author{
Dathini Hamina ${ }^{1}$, Robert Teryila Kever ${ }^{* 1}$, Markus Njida Uba ${ }^{1}$, Lola Nelson ${ }^{1}$, Habu Haruna ${ }^{1}$, Gagare A. Ayuba ${ }^{2}$, Ishaya \\ E. Friday ${ }^{3}$, Pius lorapuu Damkor ${ }^{4}$ \\ ${ }^{1}$ Department of Nursing Science, College of Medical Sciences, University of Maiduguri, Nigeria \\ ${ }^{2}$ College of Nursing Jalingo, Nigeria \\ ${ }^{3}$ Federal Medical Centre Keffi, Nigeria \\ ${ }^{4}$ Benue State University Teaching Hospital Makurdi, Nigeria
}

Received: March 14, 2018

DOI: $10.5430 /$ cns.v6n4p94
Accepted: May 6, 2018

Online Published: July 30, 2018

\begin{abstract}
This study aimed at assessing the umbilical cord care practices and separation time in healthy new-born in Maiduguri, Borno State, Nigeria. A descriptive survey design was adopted for the study. A total of 365 women attending child welfare clinic were selected through systematic random sampling technique from three health care facilities in Maiduguri Metropolis. A self-developed and validated questionnaire was used to collect information from the women on common cord care practices and knowledge of standard umbilical cord care practices. The questionnaire was pretested in State Specialist Hospital Maiduguri, Borno State and the correlation coefficient of 0.87 determined. The result of the study revealed that common cord care practices among women in Maiduguri include the use of methylated spirit, hot compress, charcoal, Vaseline and table salt. Others were mixture of methylated spirit with traditional concoctions, toothpaste and cow dung were also found to be commonly used by the mothers. The mean umbilical cord separation time of 3.5 days $( \pm 0.397)$ was observed with the unorthodox treatment of the cord. Although there was a good knowledge among the respondents with regards to standard umbilical cord care practice, there was however no commensurate practice. Therefore, there is an urgent need for cultural re-orientation most especially of women with regard and unhygienic traditional cord care practices on the new born.
\end{abstract}

Key Words: Umbilical cord, Practices, Healthy newborn, Maiduguri

\section{INTRODUCTION}

The umbilical cord is a distinctive tissue consisting of three blood vessels (one vein and two arteries) that is shielded by a substance called Wharton's jelly - which is thin and mucoid in nature. ${ }^{[1,2]}$ These blood vessels allow the flow of blood and are adapted to convey oxygen and nutrition from the mother through the placenta to the fetus and also get rid of carbon dioxide as well as other metabolic wastes from the fetus. ${ }^{[3]}$ Because of this function, the umbilical cord is seen as the lifeline of the fetus during pregnancy. However, immediately after birth of the baby, this cord is no longer needed by the baby, it therefore has to be clamped and cut close to the navel few minutes following birth. The clamp helps to prevent bleeding from the three blood vessels of the umbilical cord. ${ }^{[4]}$ The cord stumps that remain soon begin to dry, turn black and stiff. The cord stump in normal circumstances separates within 5-15 days after birth. ${ }^{[4]}$ It therefore becomes paramount that the umbilical cord which

${ }^{*}$ Correspondence: Robert Teryila Kever; Email: robertkever72@gmail.com; Address: Department of Nursing Science, College of Medical Sciences, University of Maiduguri, Nigeria. 
is now a potential portal of entry for micro-organism must be properly cared for because it allows direct communication between external and internal environment leading to septicemia or localized infection. In Africa, pregnancy and the birth of a child are prone to many superstitious beliefs. Consequently, a lot of concern and anxiety surround the baby until the umbilical cord falls off as most mothers are anxious about the time of umbilical cord fall off. In that regards, a lot of unhealthy practices are been adopted to hasten the fall of the cord with most of them becoming detrimental to the baby's health. It is no longer a story that the gravity of this problem and its attending consequences is enormous. ${ }^{[5]}$

The World Health Organization recommends improved new born care practices at birth in order to reduce neonatal morbidity and mortality. One of these essential practices especially for developing countries is a clean and dry cord which is very important in preventing early neonatal sepsis. ${ }^{[6,7]}$ This is because, the devitalized tissue of the cord stump can be an excellent medium for bacterial growth, especially if the stump is kept moist and unclean. ${ }^{[8]}$ The world health body also acknowledges that antiseptics may be helpful as against the harmful unhygienic, traditional practices which place newborns at increased risk for omphalitis. ${ }^{[7]}$

It is needful to point out that, due to cultural beliefs and anxiety about the time it takes for the cord to fall off, many African mothers result to different interventions to shorten the cord separation time. Anecdotal observation revealed that Umbilical cord infection continues to increase in Maiduguri, Borno State, leading to the death of many neonates. Unknowingly, parents carry out different unscientific practices such as the use of hot compress with sand, toothpaste, and engine oil etc in an attempt to hasten the fall-off of the umbilical cord, without the knowledge of the risk such practices predispose the child to. It is paramount to state that if these practices are not checked, the target of sustainable development goal may be a mirage in Nigeria. ${ }^{[9]}$ This research was conducted among healthy newborn, to assess the common cord practices, average time of umbilical cord separation and the knowledge of mothers on standard umbilical cord care practices in Maiduguri.

\section{MATERIALS AND METHODS}

A descriptive survey design was adopted to determine umbilical cord care practices and separation time in healthy newborn babies.

The study consisted of 570 women attending child welfare clinic - comprising 95 women from University of Maiduguri Teaching Hospital, 200 from Mohammed Shuwa Memorial Hospital and 275 from Gwange clinic. The choice of Maid- uguri as a study area was made because the town is the state capital and probably the most populous in North-eastern Nigeria. The sample size for the study was determined using Yamanes's formula. ${ }^{[10]} 371$ respondents were selected from the 3 health care centers using proportion to size as follows University of Maiduguri Teaching Hospital 76, Mohammed Shuwa Memorial Hospital 133 and Gwange clinic 162 respondents. The researchers adopted a systematic random sampling technique in selecting individual respondents from the health care centers. A self-developed and validated questionnaire on the common cord care practices and knowledge of standard umbilical cord care practices was used as instrument for the study. The instrument was reviewed by senior colleagues and later pre-tested in State Specialist Hospital Maiduguri, Borno State. Test and re-test was used to verify the reliability coefficient of the instrument. A correlation coefficient of 0.87 was found. The questionnaire was divided into three sections:

Section A consists of the socio-demographic variables such as age, level of education, religion, parity, place of antenatal care, place of delivery and age of the baby.

Section B consists of structured questions on common cord care practices.

Section $\mathrm{C}$ consists of structured questions with regards to the knowledge of mothers about standard umbilical cord practices in the management of new born babies. The questionnaire was interpreted using the following scoring system: one (1) was allotted for any correct response and zero (0) was given for wrong answer. A maximum attainable mark of 5 was considered for section B. The total score was converted into percentages. The mean percentage for the correct and incorrect answers was taken, and further compared with McDonald's standard of learning outcome measured criteria.

McDonald's standard of learning outcome measured criteria was used to categorize respondents, level of knowledge on standard umbilical cord care practices. This set of criteria was developed in order to measure the actual performance of students' learning in the educational institution. The criterion is categorized into five groups ${ }^{[11]}$ (see Table 1).

Table 1. Five groups

\begin{tabular}{ll}
\hline Level of knowledge & Composite percent of scores \\
\hline Very low & $<60 \%$ \\
Low & $60 \%-69.99 \%$ \\
Moderate & $70 \%-79.99 \%$ \\
High & $80 \%-89.99 \%$ \\
Very high & $90 \%-100 \%$ \\
\hline
\end{tabular}


Ethical clearance was obtained from the ethical review committee of University of Maiduguri Teaching Hospital before the commencement of the study. All the respondents were guaranteed of confidentiality. They were also assured that there will be no consequences if they choose not to participate in the study and that they have the right to withdraw their participation at any stage of the study. The instrument was administered by researchers themselves to the respondents during clinic days. A total of 371 copies of the questionnaire were administered however, only 365 were returned questionnaire were considered appropriate for analysis. Descriptive statistics of frequencies and percentages were used while inferential statistics (Chi-square) was used to test association between dependent and independent variables.

Table 2. Socio-demographic characteristics $(\mathrm{N}=365)$

\begin{tabular}{|c|c|c|c|}
\hline Variables & Category & Frequency & Percent \\
\hline \multirow{5}{*}{ Mothers age } & $15-19$ years & 26 & 7.1 \\
\hline & 20-25 years & 162 & 44.4 \\
\hline & 26-30 years & 113 & 31.0 \\
\hline & $31-40$ years & 59 & 16.2 \\
\hline & $\geq 41$ years & 5 & 1.4 \\
\hline \multirow[t]{2}{*}{ Religion } & Christianity & 52 & 14.2 \\
\hline & Traditional & 1 & 0.3 \\
\hline \multirow{5}{*}{ Mother's parity } & 1 & 86 & 23.6 \\
\hline & 2 & 74 & 20.3 \\
\hline & 3 & 63 & 17.3 \\
\hline & 4 & 36 & 9.9 \\
\hline & $>5$ & 106 & 29.0 \\
\hline \multirow{4}{*}{ Level of education } & No formal education & 60 & 16 \\
\hline & Primary & 62 & 18 \\
\hline & Secondary & 125 & 34.2 \\
\hline & Tertiary & 116 & 31.8 \\
\hline \multirow{5}{*}{ Post-partum period } & $<$ One month & 175 & 47.9 \\
\hline & One month & 50 & 11.2 \\
\hline & Two months & 41 & 13.3 \\
\hline & Three months & 38 & 10.4 \\
\hline & $>$ Three months & 60 & 16.4 \\
\hline \multirow[b]{2}{*}{ Place of antenatal care } & UMTH & 109 & 29.9 \\
\hline & Moh'd Shuwa Memorial & 218 & 59.7 \\
\hline \multirow{4}{*}{ Place of delivery } & Moh'd Shuwa Memorial & 167 & 45.8 \\
\hline & Gwange health center & 12 & 3.3 \\
\hline & At Home & 95 & 26.0 \\
\hline & Others & 11 & 3.0 \\
\hline
\end{tabular}

\section{RESUlts}

Table 2 shows that majority $162(44.4 \%)$ of the respondents were within the age bracket of 20-25 years, others were, 113 (31.0\%), 59 (16.2\%), $26(7.1 \%)$ and $1(2 \%)$ were within 21-30 years, 31-40 years, 15-19 years and above 40 years respectively. A large proportion $311(85.4 \%)$ of the respondent were Muslims while $52(15.2 \%)$ were Christians. Parity of the women ranges from primi to grand multiparous. Majority of the respondents $106(29.0 \%)$ were grand multiparous women while $86(23.6 \%)$ were primiparous. With regards to the level of education, $60(16.0 \%)$ had no formal education, $62(18.0 \%)$ had primary school certificate, $125(34.2 \%)$ were secondary school certificate holders while 116 (31.8\%) had tertiary education training. With respect to Post- partum period, a large proportion 175 (47.9\%) of the women were less than four weeks post-partum, 50 (11.2\%) were one month, $41(13.3 \%)$ were two months, 38 (10.4\%) were three months and $60(16.4 \%)$ were more than three months postpartum. Majority of the respondents 218 (59.7\%) received their ante-natal care in Moh'd Shuwa Memorial Hospital, 
$109(29.9 \%)$ in University of Maiduguri Teaching Hospital while $38(10.4 \%)$ received ante-natal care in Gwange health centre. Also $80(21.9 \%)$ of the respondents had their babies in University of Maiduguri Teaching Hospital, 167 (45.8\%) in Moh'd Shuwa Memorial Hospital, 12 (3.3\%) in Gwange health centre, $95(26.0 \%)$ at home while $11(3.0 \%)$ had their deliveries in other places.

Table 3. Common cord care practices and separation time $(\mathrm{N}=365)$

\begin{tabular}{llll}
\hline Variables & Category & Frequency & Percent \\
\hline & Methylated spirit & 140 & 38.4 \\
& Methylated spirit with Traditional mixture & 20 & 5.5 \\
& Tooth paste & 10 & 2.7 \\
& Dustin powder & 17 & 4.7 \\
& Traditional mixture alone & 5.5 & 2.7 \\
& Cow dung & 20 & 4.1 \\
& Vaseline & 10 & 4.9 \\
Sommon cord practices & Hot compress & 15 & 23.0 \\
& Ash and charcoal & 18 & 2.2 \\
& Charcoal & 84 & 6.3 \\
Umbilical cord falling status & Yes & 8 & 90.4 \\
& No & 23 & 9.6 \\
& $2-5$ & 330 & 76.7 \\
Time of fall off in days & $6-10$ & 35 & 13.2 \\
\hline
\end{tabular}

Note. Mean separation time (days) $=3.5( \pm 0.397)$

Table 4. Knowledge of standard umbilical cord practice $(\mathrm{N}=365)$

\begin{tabular}{lll}
\hline Variables & Correct & $\begin{array}{c}\text { Incorrect } \\
\boldsymbol{f ( \% )}\end{array}$ \\
\hline Washing of hands before cleaning the stump & $348(96.7)$ & $17(3.3)$ \\
Discarding of spirited swap after every single use & $326(89.3)$ & $39(10.7)$ \\
Stump should be cleaned after every diaper change & $327(89.6)$ & $38(10.4)$ \\
Methylated spirit is always the best choice for umbilical cord cleaning & $315(86.3)$ & $50(13.7)$ \\
Umbilical cord should always be kept dry & $341(93.4)$ & $24(6.6)$
\end{tabular}

Note. Mean responses for correct answers $=91.1 \%$

Table 3 revealed that majority $140(38.4 \%)$ of the respondents used methylated spirit, 84 (23.2\%) used hot compress. Other methods used by the respondents were; charcoal, 23 (6.3\%), Methylated spirit with Traditional mixture 20 (5.5\%), Dustin Powder 17 (4.7\%) and cow dung 10 (2.7\%). Other methods includes: toothpaste 10 (2.7\%), salt 18 (2.2\%) and Vaseline $15(4.1 \%)$. With regards to the separation time, the results also showed that $280(76.7 \%)$ babies had their cord separated within 2-5 days, 48 (13.2\%) within 6-10 days 2 $(0.6 \%)$ within $11-20$ days while there was no response from $35(9.5 \%)$.

Table 4 shows the distribution of responses on the overall knowledge of standard umbilical cord practices; the calcu- lated mean scores of correct answers given by the respondents is $91.1 \%$. This implies that the respondents have very high knowledge of Standard Umbilical cord Practices.

The total obtainable mark for knowledge on standard cord care practices was 5 . The mean scores for knowledge of respondents for each demographic variable in Table 5 were obtained. The respondents scored from 2-5. The results also showed that the mean and standard deviation scores of respondents according to their age range were: 2.4 (1-6), 3.1 (1.8), 4.4 (0.6) and 4.7 (0.3) for 15-19, 20-25, 26-30 and greater or equal to 31 years respectively. Mean and standard deviation scores regarding level of education of respondents were 2.0 (1.0), 2.1 (0.9), 3.8 (1.1) and 4.5 (0.5) for non- 
formal education, primary, secondary and tertiary education respectively. Respondents scored 1.9 (1.1), 4.0 (1.0), 4.1 $(0.8), 4.2(0.8)$ and $4.3(0.7)$ for para 1, 2, 3, 4 and greater or equal to para 5 accordingly.
Table 6 shows the calculated Chi-square value of 53.59 and an index or critical value $(c-r)$ of 31.41 . This implies that the critical value was significantly less than the calculated value of chi-square. This therefore means that cord care practices have a significant relationship with time of separation.

Table 5. Mean and standard deviation of knowledge scores for mothers by age, level of education and parity

\begin{tabular}{|c|c|c|c|c|c|}
\hline & Variable & Frequency & Percent & Knowledge Mean scores & $S D$ \\
\hline \multirow{4}{*}{ Age (years) } & $15-19$ & 26 & 7.1 & 2.4 & 1.6 \\
\hline & $20-25$ & 162 & 44.4 & 3.1 & 1.8 \\
\hline & $26-30$ & 113 & 31.0 & 4.4 & 0.6 \\
\hline & $\geq 31$ & 64 & 17.5 & 4.7 & 0.3 \\
\hline \multirow{4}{*}{ Level of education } & Non formal & 60 & 16 & 2.0 & 1.0 \\
\hline & Primary & 62 & 18 & 2.1 & 0.9 \\
\hline & Secondary & 125 & 34.2 & 3.8 & 1.1 \\
\hline & Tertiary & 116 & 31.8 & 4.5 & 0.5 \\
\hline \multirow{5}{*}{ Parity } & 1 & 86 & 23.6 & 1.9 & 1.1 \\
\hline & 2 & 74 & 20.3 & 4.0 & 1.0 \\
\hline & 3 & 63 & 17.3 & 4.1 & 0.8 \\
\hline & 4 & 36 & 9.9 & 4.2 & 0.8 \\
\hline & $\geq 5$ & 106 & 29.0 & 4.3 & 0.7 \\
\hline
\end{tabular}

Table 6. Contingency table of umbilical cord care practice in relation to time of cord fall off of the cord

\begin{tabular}{|c|c|c|c|c|c|c|c|}
\hline Category & $\leq 5$ days & 6-10 days & $>10$ days & Total & $c-r$ & $\chi^{2}$ & Decision \\
\hline Methylated spirit & $109(120.8)$ & $30(18.41)$ & $1(0.77)$ & 140 & \multirow{12}{*}{31.41} & \multirow{12}{*}{53.59} & \multirow{12}{*}{ significan } \\
\hline Methylated spirit + traditional mixture & $18(17.26)$ & $2(2.63)$ & $0(0.11)$ & 20 & & & \\
\hline Toothpaste & $8(8.63)$ & $1(1.32)$ & $1(0.055)$ & 10 & & & \\
\hline Dustin powder & $1(14.67)$ & $6(2.22)$ & $0.0(0.09)$ & 17 & & & \\
\hline Traditional mixture alone & $18(17.26)$ & $2(2.63)$ & $0(0.11)$ & 20 & & & \\
\hline Cow dung & $7(8.63)$ & $3(1.32)$ & $0.0(0.055)$ & 10 & & & \\
\hline Vaseline & $14(12.95)$ & $1(1.97)$ & $0(0.082)$ & 15 & & & \\
\hline Salt & $18(15.53)$ & $0.0(2.37)$ & $0.0(0.10)$ & 18 & & & \\
\hline Hot compress & $84(72.49)$ & $0(11.05)$ & $0.0(0.46)$ & 84 & & & \\
\hline Ash and charcoal & $8(6.90)$ & $0.0(1.05)$ & $0.0(0.04)$ & 08 & & & \\
\hline Charcoal & $20(19.85)$ & $3(3.02)$ & $0.0(0.13)$ & 23 & & & \\
\hline Total & 315 & 48 & 2 & 365 & & & \\
\hline
\end{tabular}

\section{Discussion}

The current study aimed at assessing the umbilical cord care practices and separation time in healthy new-born. The mean age of respondents was $32 \pm 7.2$. Majority 162 (44.4\%) of the respondents fall within 20-25 years. This shows that the respondent (mothers) were within the acceptable child bearing age. ${ }^{[9]}$ To the best of the researcher's knowledge, there are no published studies conducted on common cord practices, knowledge of mothers on standard cord care practices and time of cord separation in north-eastern Nigeria. Therefore the researchers were unable to compare these finding 98 with the local population as local studies on the topic are still scarce. Nevertheless, a few studies in developed countries where exposure and level of education among mothers is higher demonstrated a sharp contrast.

Data from this study demonstrate that the common cord care practices among women in Maiduguri includes; use of methylated spirits, hot compress, charcoal, Vaseline and table salt. Others were a mixture of methylated spirit with traditional concoctions, toothpaste and cow dung. This report is contrary to mothers in tertiary health care institutions in developed $^{[12-14]}$ and other developing ${ }^{[5,15,16]}$ countries where 
chlorhexidine and other antiseptics are used. It is paramount to note that, although majority of respondents claimed to have been using methylated spirit which is one of the WHO's acceptable antiseptics for umbilical cord care; however a significant number of the respondents used unhygienic concoctions in the care of baby's cords in addition to the conventional method. The use of these unhygienic applications may probably be one of the reasons for high prevalence of neonatal sepsis and high neonatal mortality in the study area. The use of these unhygienic concoctions reported in this current study lends support to the report of Muktar in Kano, north-western Nigeria. ${ }^{[1]}$ There is therefore no doubt that use of these unhygienic concoctions observed in this study may be attributed to mothers' cultural beliefs.

Shorter umbilical cord separation time of $3.5( \pm 0.397)$ days was observed in this current study compared to slightly higher mean values of 4.2 days and 8.7 days among infants in Kano and Ilorin respectively. ${ }^{[14,18]}$ Contrary to this shorter umbilical cord separation time reported in this study, there has been several studies in developed countries of the world that reported a longer but safer time of cord separation, depending on the care provided. ${ }^{[14,19-21]}$ The observed mean time of cord separation as reported in most of these studies conducted in developed countries is generally 10 days, however few studies reported a mean cord separation times of 7 days. ${ }^{[22-24]}$ The shorter cord separation time reported in this current study may be attributed to the "strong" but unhygienic concoctions often used by mothers in this part of the world.

In our study, cord care practices were significantly related to time of cord separation. This finding is consistent with that of Mullany et al. ${ }^{[6]}$ and Monu and Okolo. ${ }^{[25]}$ Monu and Okolo further explained that traditional concoction of chalk and herbs with desiccating properties might lead to the cord stump falling off within 2 days after birth in communities of Nigeria. The results from our study confirm this observation and further lend support to the assertion "that cord separation is rapid in communities of developing countries where infants are exposed to unhygienic practices".

Mother's knowledge on umbilical cord care practices irrespective of their age, educational level and parity was found to be above average in our study and the overall mean score of correct answers given by the respondents was $91.1 \%$ indicating a very high level of knowledge on standard cord care practices. These findings are similar to the findings of Castalino et al. ${ }^{[26]}$ who reported high level of knowledge on standard umbilical cord care among mothers in India. The high level of knowledge observed among the respondents may be attributed to their parity, level of education and age that are bedrock of experience. It may also be attributed to the health education they receive during ante-natal care. Furthermore, it was also observed that multiparas and grand multiparas recorded the highest mean of knowledge of 4.1 $( \pm 0.8)$ and $4.3( \pm 0.7)$ respectively. The result is not surprising as they may had attended ante natal clinic during their previous pregnancies and probably sat under the tutelage of health care professionals. Although, studies on the relationship between parity and knowledge on standard umbilical cord care practice is not yet visible, the result of this study is an indication that increased parity can positively improve peri-natal knowledge among mothers.

Furthermore, our study observed that majority of the mothers had formal education and a wealth of experiences acquired during antenatal visits judging by their knowledge on standard cord care practices and number of parity, it is needful to point out that their level of education and wealth of experiences does not translate to good and standard healthy cord care practices. This result aligned with that of Oyedeji ${ }^{[27]}$ in South-Western Nigeria. The lack of positive influence of mother's knowledge and experiences on the practices of cord care reported in our study may be attributed to the overriding impact of cultural beliefs and anxiety that surrounds delay in the cord fall off.

\section{Implication for nursing}

Nurses form the majority of workforce within health care industry. The need to be fully integrated and involved in the achievement of proper health education during antenatal visits cannot be overemphasized. Translating research findings into practice is important for the nursing profession as this could increase the standard of knowledge and practice, improve quality of health care rendered to clients and prevent unnecessary waste of time and resources thus resulting in reduced cost of treatment.

\section{Conclusions}

In conclusion, majority of mothers were knowledgeable of standard umbilical cord care practices as recommended by the World Health Organisation, however commensurate practice was elusive since most mothers were still involved in traditional cord care practices which are harmful.

\section{Recommendations}

Based on the findings, the following recommendations were made:

(1) There is the need for public and cultural re-orientation. Government in collaboration with non-governmental organizations should develop a protocol and update the mothers on the dangers of harmful and unhygienic traditional cord care practices. 
(2) Application of non-evidence based, dangerous and unhygienic substances to the umbilical cord should be discouraged during ante-natal clinic visits.

\section{ACKNOWLEDgements}

We, the authors are very grateful to our diligent data collectors, the matrons, respondents and supporting staff of the post-natal clinics for their team spirit. We thank the management of UMTH, Mohammed Shuwa Memorial Hospital, Gwange clinic and the entire staff of Department of Nursing Science, University of Maiduguri for their moral and intellectual support particularly at proposal stage of the study.

\section{Conflicts OF InTEREST Disclosure}

The authors declare they have no conflicts of interest.

\section{REFERENCES}

[1] London ML, Ladewig PW, Ball JW, et al. Maternal and child Nursing care. 2nd ed. Person: Upper Saddle River; 2007.

[2] World Health Organization. Essential Newborn Care Manual. Geneva. 2006.

[3] Association of Woman's Health, Obstetric and Neonatal Nurses (AWHONN). Evidence-based clinical practice guideline: cord care. Neonatal Skin Care. 2nd ed. Washington, DC; 2007.

[4] Cincinnati Children. Babies and infants home care/umbilical cord care. Cincinnati Children Hospital Medical Centre. 2007. Available from: http://www.cincinnatichildren's.org/healt $\mathrm{h} /$ info/newborn/home/cord-care.htm

[5] Vural G, Kisa S. Umbilical cord care: a pilot study comparing topical human milk, povidone-iodine, and dry care. J Obstet Gynecol Neonatal Nurs. 2006; 35: 123-128. PMid: 16466360. https : //doi.org/10.1111/j.1552-6909.2006.00012.x

[6] Mullany LC, Darmstadt GL, Khatry SK, et al. Umbilical Cord Care: A Pilot Study Comparing Topical Human Milk, Povidone-Iodine, and Dry Car. Journal of Obstetric Gynecologic \& Neonatal Nursing. 2006; 35(1): 123-128. PMid: 16466360. https://doi.org/10.1 $111 / \mathrm{j} .1552-6909.2006 .00012 . \mathrm{x}$

[7] Marsh DR, Darmstadt GL, Moore J, et al. Advancing newborn health and survival in developing countries: a conceptual framework. Journal of Perinatology. 2002; 22(7): 572-576. PMid: 12368975. https://doi.org/10.1038/sj.jp.7210793

[8] Waiswa P, Peterson S, Tomson G, et al. Poor newborn care practices-a population based survey in eastern Uganda. BMC Pregnancy and Childbirth. 2010; 10: 9. PMid: 20178626. https://doi.org/10 .1186/1471-2393-10-9

[9] WHO. Care of the umbilical cord? A review of the evidence. WHO/RHT/MSM/98. 4th ed. Geneva. 1998

[10] Uzoagulu AE. Practical Guide to Writing Research Project Reports in Tertiary Institutions. Enugu, Cheston Limited, Nigeria. 2011; 53-55.

[11] McDonald ME. Systemic assessment of learning outcome: Developing multiple choice examinations. Sudbury MA: Jones and Bartiett Publishers; 2002.

[12] Zupan J, Garner P, Omari AA. Topical umbilical cord care at birth. Cochrane Database Syst Rev. 2004(3): CD001057. https: //doi.org/10.1002/14651858.CD001057.pub2

[13] Evens K, George J, Angst D, et al. Does umbilical cord care in preterm infants influence cord bacterial colonization or detachment? J Perinatol. 2004; 24: 100-104. PMid: 14762447. https: //doi.org/10.1038/sj.jp.7211027

[14] Pomeranz A. Anomalies, abnormalities, and care of the umbilicus. Pediatr Clin North Am. 2004; 51(3): 819-27. PMid: 15157600. https://doi.org/10.1016/j.pcl.2004.01.010

[15] Chamnanvanakij S, Decharachakul K, Rasamimaree P, et al. A randomized study of 3 umbilical cord care regimens at home in Thai neonates: comparison of time to umbilical cord separation, parental satisfaction and bacterial colonization. J Med Assoc Thai. 2005; 88: 967-972. PMid: 16241027. Available from: http://www.ncbi.nlm.nih.gov/pubmed/16241027

[16] Aygun C, Subasi A, Kucukoduk S. Timing of umbilical cord separation and neonatal intensive care unit practices. Am J Perinatol. 2005; 22: 249-251. PMid: 16041634. https ://doi.org/10.1055/s-2 005-870661

[17] Mukhtar Y, Iliyasu Z, Wudil BJ. Survey of umbilical cord care and separation time in healthy newborn in Kano. Nigerian Journal of Paediatrics. 2011; 38(1): 12-19. https ://doi.org/10.4314/nj p.v38i4.72280

[18] Oladokun RE, Orimadegun AE, Olowu JA. Umbilical cord separation time in healthy Nigeria newborns. Nigerian Journal of Paediatrics. 2005; 32(3): 19-25. https://doi.org/10.4314/njp.v32i1.12 096

[19] Arad I, Eyal F, Fainmesser P. Umbilical care and cord separation. Arch Dis Child. 1981; 56: 887-888. PMid: 7030227. https : //doi.org/10.1136/adc.56.11.887

[20] Mullany LC, Darmstadt GL, Tielsch JM. Role of antimicrobial applications to the umbilical cord in neonates to prevent bacterial colonization and infection: a review of the evidence. Pediatr Infect Dis J. 2003; 22(11): 996-1002. PMid: 14614373. https : //doi.org/10.1097/01.inf.0000095429.97172.48

[21] Imdad A, Bautista RM, Senen KA, et al. Umbilical cord antiseptics for preventing sepsis and death among newborns. Cochrane Database Syst Rev. 2013; CD008635. https : //doi.org/10.1002/146518 58. CD008635.pub2

[22] Mir F, Tikmani SS, Shakoor S, et al. Incidence and etiology of omphalitis in Pakistan: a community-based cohort study. J Infect Dev Ctries. 2011; 5(12): 828-33. PMid: 22169780.

[23] McConnell TP, Lee CW, Couillard M, et al. Trends in umbilical cord care: Scientific evidence for practice. New born and Infant Nursing Reviews. 2004; 4(4): 211-222. https ://doi.org/10.1053/j.na inr.2004.09.004

[24] Novack AH, Mueller B, Ochs H. Umbilical Cord Separation in the Normal New born. Am J Dis Child. 1988; 142(2): 220-223. PMid: 3341328 .

[25] Monu JU, Okolo AA. Neonatal necrotizing fasciitis: a complication of poor cord hygiene: report of three cases. Ann Trop Paediatr. 1990; 10: 299-303. https ://doi.org/10.1080/02724936.199 0.11747446

[26] Castalino F, Nayak BS, D’Souza A. Knowledge and practices of postnatal mothers on new born care in tertiary care hospital of Udupi district. Nitte University Journal of Health Science. 2014; 4(2): 98101 .

[27] Oyedeji GA, Oyedeji PO, Elemile PO, et al. Cords care practices of South Western-Western Nigerian mothers. Journal of Tropical Medicine. 2008; 3(2): 15-18. Available from: http://medwellj ournals. com/abstract/?doi=ijtmed . 2008.15.18 